\title{
Crackdown on Spying Damages US Science, Says Chinese-Born Physicist
}

\author{
Sakharov Prize winner decries the pervasive suspicion faced by \\ Chinese-American scientists.
}

By Griffin Wilce

$\mathrm{T}$ he US government has recently taken a hard line toward economic espionage, arresting several researchers for allegedly sharing technology secrets or for hiding affiliations with the Chinese government. But this crackdown could have unwanted repercussions. "Innocent Chinese-American scientists are being unfairly targeted,"

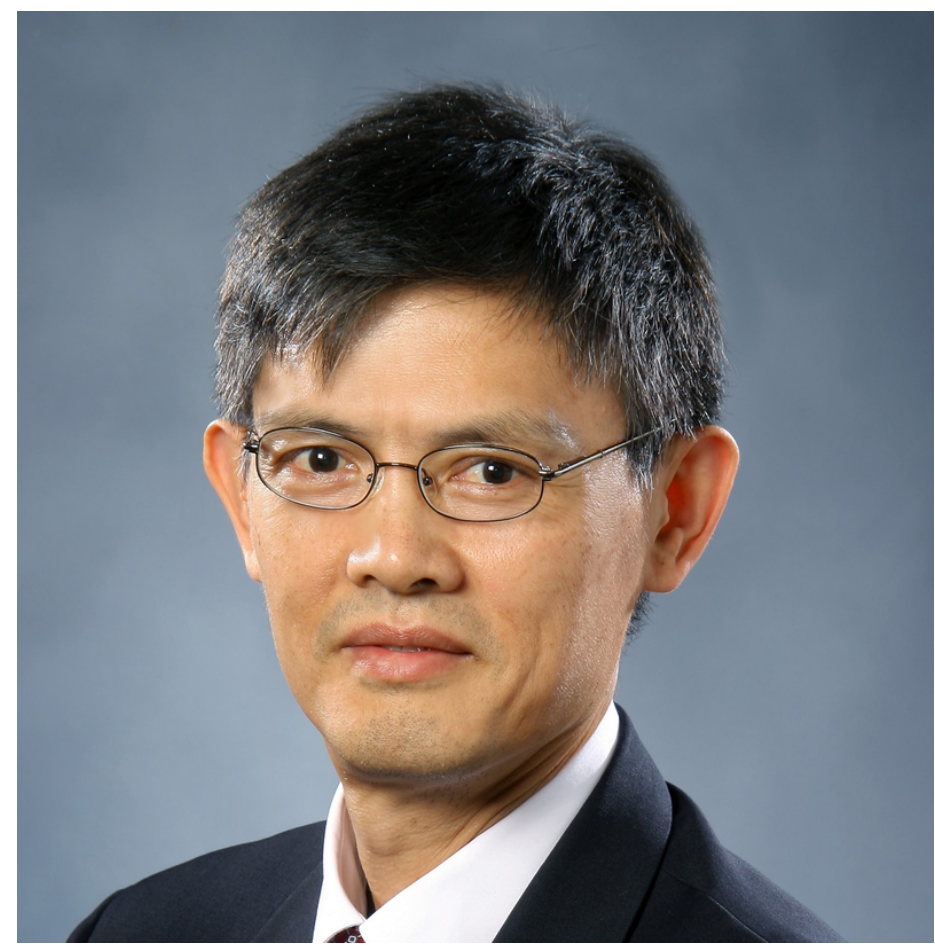

Xiaoxing Xi, of Temple University, is a 2020 recipient of the APS Andrei Sakharov Prize.

Credit: Pennsylvania State Univ. according to physicist Xiaoxing Xi, one of two 2020 winners of the APS Andrei Sakharov Prize. Xi, of Temple University, Philadelphia, spoke at the 2021 APS March Meeting. He said that this targeting by national security agencies could have disastrous consequences for US research, and he urged scientists to defend their Chinese colleagues from injustice.

Xi has personal experience with this matter. In May 2015, he was arrested by the FBI on charges of sending sensitive American technology to China. But the indictment "was totally false," Xi told his APS audience. His FBI interrogators "knew nothing about how science is done, and they saw routine academic activities as criminal." Four months later, the charges were dropped, and $X i$ was released, after independent experts convinced federal prosecutors that the schematics Xi had shared with his Chinese colleagues did not describe any sensitive technology [1]. Since then, Xi has worked to increase the visibility of cases like his, which led the Sakharov Prize committee to honor him last year.

In his talk, Xi highlighted several misconceptions voiced by members of the US government. For example, in a video clip Xi showed, former Secretary of State Mike Pompeo commented on Chinese students and employees. "Too many of them come here to steal our intellectual property and to take this back to their country. Communist China is already within our borders." However, around $90 \%$ of the Chinese graduate students who study in the US stay here, Xi said, and the vast majority do open research that contributes to US science. Xi said that talk of Chinese spies "within our borders" is reminiscent of the McCarthyism of the 1950s, when hundreds of Americans were 
falsely accused of being Soviet spies.

Another misconception is that academic collaborations between Chinese and American scientists are helping China leapfrog the US in technology development-a perceived loss to US taxpayers who support these collaborations. Xi argued that open scientific exchange is essential to US scientific progress. He cited a 2012 State Department report that said US-China cooperation "accelerated scientific progress in the United States, providing significant direct benefit to a range of US technical agencies." Xi also quoted documentation from a National Science Foundation program that has funded research collaborations with many countries, including China, for over a decade: "International engagement will be critical to keeping the US globally competitive at the frontiers of knowledge."

Over the past few years, the US Department of Justice (DOJ) has arrested many scientists as part of an initiative to counter intellectual property theft. Xi showed a list of eight Chinese-American scientists whose cases were ultimately dropped by the DOJ. Still, many Chinese scientists have left the US fearing such prosecutions. Xi argued that part of the problem is that the rules regarding reporting of conflicts of interest, such as international collaborations, are unclear. The
DOJ treats failures to report international connections as criminal offenses, but Xi advocated for treating them as academic misconduct.

Xi has been active in publicizing a 2019 report on fundamental research and national security produced by JASON, an independent group of scientists that advises the US government. This report provides backing for many of Xi's arguments, showing that not only is academic collaboration with China beneficial to the US but also that openness and inclusion of foreign researchers in basic research is essential. It also urges the government to clarify conflict-of-interest reporting rules and to avoid criminalizing those who break them. "The question is, 'are Chinese professors, scientists, and students spies?' The JASON report answered unequivocally, 'no,"' Xi said. He concluded by urging scientists to defend their Chinese colleagues against unjust prosecutions and to work to safeguard open basic research at US universities.

Griffin Wilce is a Physics science writing intern.

\section{REFERENCES}

1. Xi gives further details of his case in a Harvard Physics Colloquium lecture (YouTube), 25 January 2021. 